\title{
Meta-Analysis of the Effects of Various Physical Therapy Method about Shoulder Adhesive Capsulitis: The Cases of Domestic Research
}

\author{
Chan Myeong Kim \\ Korea Safety Health Environment Foundation, Work Environment Health Center, Cheongju, Republic of Korea
}

\begin{abstract}
Purpose: The main purposes of this study are to identify the degree of effect size and variables related to it, on the effect of physical therapy on shoulder adhesive capsulitis.

Methods: This study were collected 8 studies published between 2010.01.01. and 2020.08.01. The Analysis result confirmed 16 effect size data, the random effect model was chosen because of the heterogeneity of the data.

Results: First, full case showed the largest mean effect size $3.28(p<0.001)$. Second, Size of the effect according to hands on + off intervention the 5.17 ( $p>0.344)$. Third, Number of participants showed 15 or more effect size $4.19(p<0.002)$. intervention period showed 8 weeks effect size 5.12 ( $p>0.425)$. Number of intervention showed 14 or less effect size $3.99(p>0.061)$. Publication type showed thesis effect size 4.34 ( $p<0.003)$. Finally, 'Trim and Fill' result confirmed that the calibration effect size is $1.71(p<0.001)$.

Conclusion: We were able to confirm that physical therapy had great effect on shoulders adhesive capsulitis, and that the effect differed according to the methods of intervention, the methods of evaluation.
\end{abstract}

Keywords: Adhesive capsulitis, Physical therapy, Meta-analysis

\section{서 론}

근골격계 질환은 신체활동의 감소나 과사용으로 인해 많이 발생하 고 있으며, 특히 어깨 관절의 통증은 허리통증 다음으로 자주 접하게 되는 부위이다.' 어깨관절 주위 조직의 퇴행성 변화가 나타나면 통증 과 운동제한을 가져오는데 이러한 질환을 오십견(Frozen shoulder), 동결견 또는 유착성 관절낭염(Adhesive capsulitis)이라고 하고, ${ }^{2}$ 오십 견이 발생되면 회전근개, 관절 활액막, 관절낭, 위팔두갈래근힘줄 및 주위 조직을 침범하는 퇴행성 변화의 결과로 통증과 운동제한을 가 져오게 되고, 유병률은 전체 인구의 2-5\%로 보고되고 있다.3, 일반적 으로 어깨관절의 벌림 뿐만 아니라 안쪽돌림과 가쪽돌림의 감소가 특징적이며, 진단 기준으로 수동적인 벌림이 $100^{\circ}$ 이하(정상의 $75 \%$ ), 굽힘 $140^{\circ}$ 이하(정상의 $80 \%$ )로 정의되고 있다. ${ }^{5}$ 또한 목 부위의 신경근 병변과 같이 신경적인 근 약화를 유발하지는 않지만 통증에 의해 어 깨관절의 굽힘과 가쪽돌림의 감소가 나타나고 탄력과 함께 유연성 이 소실되고 관절의 섬유화를 동반한 만성염증의 형태로 인하여 일
상생활 동작에 어려움을 초래하고, ${ }^{4,6}$ 심각한 통증과 관절가동범위의 제한이 나타나며 통증이 심할 경우 수면 장애까지 일으키는 질환이 므로 적극적이고 다양한 중재가 필요하다.

임상적으로는 주로 통증이 심한 시기, 통증과 함께 점차 관절가동 범위가 제한되는 시기, 마지막으로 통증의 소실과 함께 운동 범위가 회복되는 세 시기로 나누어지며 유발인자의 유무에 따라 특발성과 속발성으로 구분된다. ${ }^{8}$ 발병원인은 아직까지 정확히 밝혀지지 않고 있으며, 외상, 고정, 수술, 당뇨, 갑상선질환 등의 내분비 질환 및 심폐 질환이나 뇌졸중 등의 신경계 질환 등이 원인으로 알려져 있다. ${ }^{9}$ 과거 에는 1-2년 정도 시간이 지나고 나면 자연치유 된다고 알려져 있어서 대부분의 환자들은 치료하지 않더라도 수개월 내지 수 년 동안에 걸 쳐 부분적으로 혹은 완전 회복되는 질환으로 이를 가볍게 생각하는 경향이 있었지만, 적절한 치료를 받지 못하면 장애가 지속된다고 알 려지면서 현재 여러 가지 치료방법이 고안되어 적용되고 있다. ${ }^{10}$ 유착 성 관절낭염의 치료 목표는 어깨 관절의 통증을 감소시키고 관절 가 동 범위의 향상을 통하여 운동성을 촉진함으로써 정상적인 기능을 
회복시키는 것이다." 수술적 접근도 치료방법으로 가능하지만 대부 분의 환자들은 보존적 치료만으로도 큰 효과를 볼 수 있고, 보존적 치료로는 전기치료, 관절가동술, 스트레칭, 도수치료 등이 있으며 그 중에서 스트레칭의 비중이 큰 편이다. ${ }^{12}$ 또한 어깨관절 가동범위의 회 복을 위해 능동, 수동 혹은 이들을 복합적으로 계획하여 적절한 스 트레칭을 시행할 경우 유착성 관절낭염으로 인한 관절가동범위 제 한과 통증을 회복할 수 있는 것으로 제시된 바 있다.12

현재까지 유착성 관절낭염에 대한 개별 치료효과들을 확인하기 위한 연구는 많이 시행되었지만, 객관적이고 체계적인 종합 결론을 도출해낸 연구는 미흡한 실정이다. 메타분석은 같은 주제로 시행된 여러 개별 연구들을 분석하여 통합하고자 하는 의도로 이루어지는 연구 방법이며, ${ }^{13}$ 장점으로는 첫째, 일련의 연구결과들을 통합하는데 있어 체계적이며 정확한 결론을 내릴 수 있고, 둘째, 사용 가능한 자 료들의 여러 결점이 지니는 편견을 통제할 수 있으며, 셋째, 모집단의 평가가 가능하며, 넷째, 복잡한 통계를 사용할 때 연구방법, 연구대 상, 범위, 조건 그리고 실험기간 사이의 관계를 동시에 규명할 수 있다 는 점이다..$^{14,15}$ 단점으로는 결과에 초점을 맞추고 있어 중재변수의 개 입이나 상호작용 효과를 무시함으로써 한 연구의 결과를 지나치게 단순화시킬 수도 있다. ${ }^{1415}$ 하지만 개별연구의 표본을 종합하여 좀 더 큰 표본을 가지고 가설을 검정하기 때문에 통계적 검정력을 높일 수 있으며, 서로 상충되는 연구결과가 있을 때 그 원인이 어디에 있는지 살펴볼 수 있는 기회를 주는 등의 장점으로 인하여, 오늘날 의학, 보 건학, 간호학, 교육학 등의 학문영역에서 특히 많이 사용되고 있는 연 구방법이다.14,15

본 연구에서는 유착성 관절낭염에 대해 물리치료를 적용한 국내 선행 연구들을 수집하여 시각통증척도의 감소에 물리치료 방법에 따라 어떠한 효과크기를 나타내는지 알아보고 최근까지의 국내 유 착성 관절낭염 물리치료 연구들에 대한 현황을 파악하고 체계적 분 석과 객관적인 효과크기 수치를 제시하는 결론을 도출하고자 한다.

\section{연구 방법}

\section{1. 연구 설계 및 연구 절차}

본 연구의 연구 대상은 어깨의 유착성 관절낭염이고 중재방법은 물 리치료 중재이며, 비교집단은 대상 중재와 다른 중재 방법이다. 연구 결과는 시각 통증 척도이며, 연구 설계 유형은 사전-사후 무작위대조 시험 설계방식의 실험 연구로 선정하였다.

\section{2. 자료 선정}

핵심 질문을 '유착성 관절낭염에 대한 물리치료의 관련 변인은 무엇 인가?'로 구성하였으며, 구체적인 선정기준은 다음과 같다. 1) 유착성
관절낭염 진단을 받은 환자를 대상으로 한 연구, 2) 물리치료 중재가 제시된 연구, 3) 통계적 수치가 제시되어 있는 연구, 4) 사전-사후 무작 위 대조시험 설계방식의 실험연구, 5) 2010년 1월 1일-2020년 8월 1일까 지의 연구. 배제기준은 다음과 같다. 1) 진단, 약물, 주사, 침, 수술을 적 용한 연구, 2) 사전-사후 무작위 대조시험 설계방식이 아닌 연구, 3) 통 계적 수치가 없는 연구, 4) 전문(Full text)을 얻을 수 없는 연구.

문헌 검색과 선정 전 과정은 PRISMA의 체계적 문헌고찰 흐름도에 의거하여 수행하였다. ${ }^{16}$ 한국학술정보(KCI), 학술연구정보(RISS)의 데 이터베이스를 사용하였고 검색 주제어는 'frozen shoulder'를 사용하여 총 213건의 문헌이 검색되었다. 자료선정의 과정은 본 연구자와 물리치 료학 분야 전문가에 의해 시행되었고 문헌관리는 Mendeley와 Excel을 사용하였다. 1 차로 원문의 제목과 초록을 통해 확인하고, 이후 선정기 준과 제외기준에 따라 원문을 상세히 검토하여 선정하였다(Figure 1).

\section{3. 연구의 비뚤림 위험 평가}

최종 선정된 8편의 연구에 대해서, Cochrane Library에서 개발한 Risk of bias검증 도구와 Review manager 5.3 프로그램을 이용하여 비뚤림 위험 평가를 진행하였다.

\section{4. 데이터 코딩}

본 연구는 단일집단(사전-사후검사) 메타분석 방법을 사용하였으며,

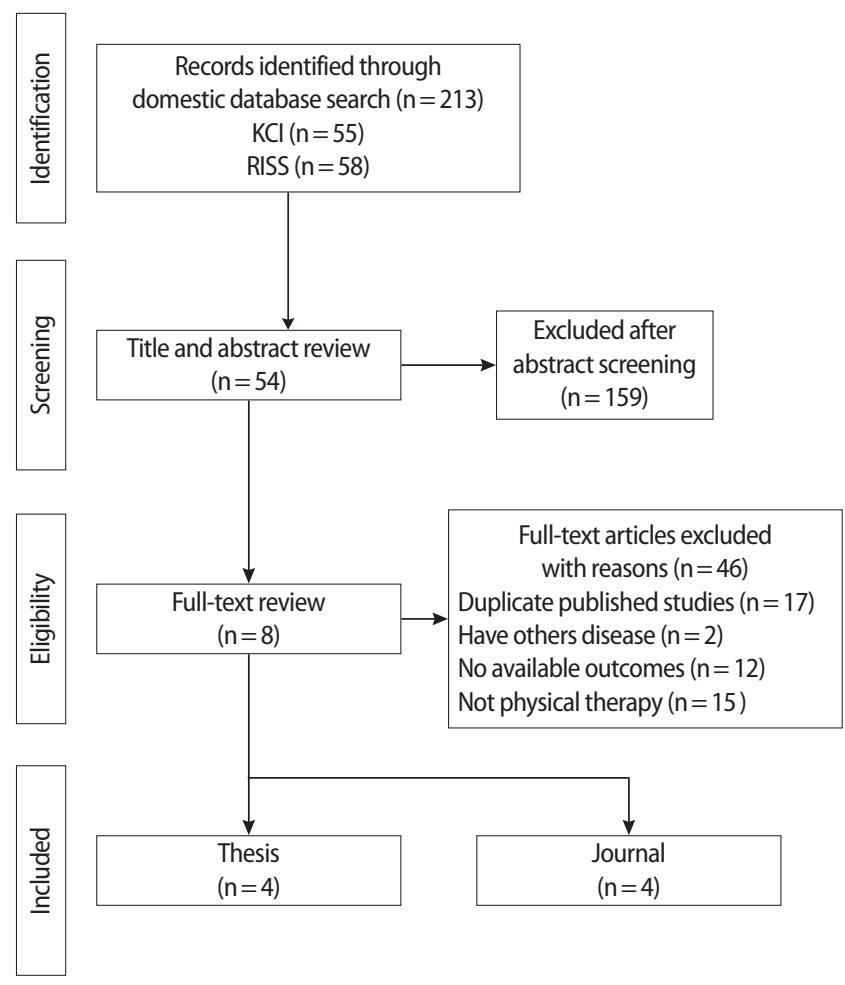

Figure 1. The picture of PRISMA flow chart. 
실험별로 사전, 사후평균, 표준편차 값을 가진 연구만을 선택하였고 수집한 자료는 연구자명, 치료유형, 중재 방법, 평가 방법, 대상자 수, 치료기간, 치료횟수, 논문명 순으로 엑셀에 입력하여 코딩시트를 구 성하였으며, 코딩 데이터는 R 프로그램에 사용할 수 있도록 Csv 파일 형태로 변환하여 분석에 사용하였다. 음수 결과를 보이는 평가인 VAS의 경우 사전 평균, 표준편차를 사후 평균, 표준편차의 값과 모두 바꾸어 효과크기가 모두 양수로 제시되도록 계산하여 문제점을 해 결하고 종합적인 결론을 도출하였다.17

\section{5. 자료 분석}

1) 통계 처리

$\mathrm{R}$ 프로그램의 패키지에서 'meta'와 'metafor'를 이용하였으며, 각기 다 른 개별 연구들의 다른 중재 유형과 비뚤림 위험 다양성이 크다는 것 을 인정하기 때문에 무선효과모형을 적용하여 효과크기를 산출하였 다. 또한, 변수의 유형에 따라 범주형 변수는 Meta-ANOVA로, 연속형 변수는 Meta-Regression으로 조절효과 분석을 하였다. ${ }^{17}$

\section{2) 효과크기의 해석}

효과크기는 표준화된 평균 차이로 해석하며, 교정된 효과크기(g)를 해석하는 방식은 Cohen's의 d해석과 같다.16

$$
\begin{aligned}
& \text { (1) 작은 효과크기: } \mathrm{ES}_{\mathrm{sm}} \leq 0.20 \\
& \text { (2) 중간효과크기: } 0.20<\mathrm{ES}_{\mathrm{sm}}<0.80 \\
& \text { (3) 큰 효과크기: } \mathrm{ES}_{\mathrm{sm}} \geq 0.80
\end{aligned}
$$

\section{3) 이질성 검증}

효과 크기 간의 차이를 효과 크기의 이질성이라 한다. 연구 간의 효과 크기의 동일성을 검증할 때 사용되는 것이 $\mathrm{Q}$ 와 $\mathrm{df}$ 값이며, 이질성의 비율은 $\mathrm{I}^{2}$ 으로 나타내고 $\mathrm{I}^{2}$ 통계치는 전체 분산에 대한 실제 연구 간 분산의 비율을 나타내며, 개별적인 연구들에서 산출된 효과크기들 의 이질성 정도를 나타낸다. ${ }^{18} \mathrm{I}^{2}$ 은 총 분산(전체 관찰 분산)에 대한 실 제(연구 간) 분산의 비율을 나타내고, 일반적으로 $\mathrm{I}^{2}$ 이 $25 \%$ 이면 작은 정도의 이질성으로, $50 \%$ 이면 중간 정도의 이질성으로, $75 \%$ 이상이면 이질성이 매우 큰 것으로 해석한다. ${ }^{18}$

\section{결 과}

본 연구의 전체 효과크기는 $\mathrm{ES}=3.28$ 이고, 큰 효과크기로 통계적으로 유의하게 나타났으며 $(\mathrm{p}<0.05), \mathrm{I}^{2}$ 값이 $91 \%$ 로 $75 \%$ 이상이므로 이질성 은 크다고 할 수 있다(Figure 2). 중재유형에 따른 분석 결과 Hands on+off 중재에서 높게 나타났으며, 95\%신뢰구간에서 모두 통계적으 로 유의하게 나타났다. 그러나 효과 크기의 차이 $\mathrm{Q}$ 값이 $2.13(\mathrm{df}=2)$ 로

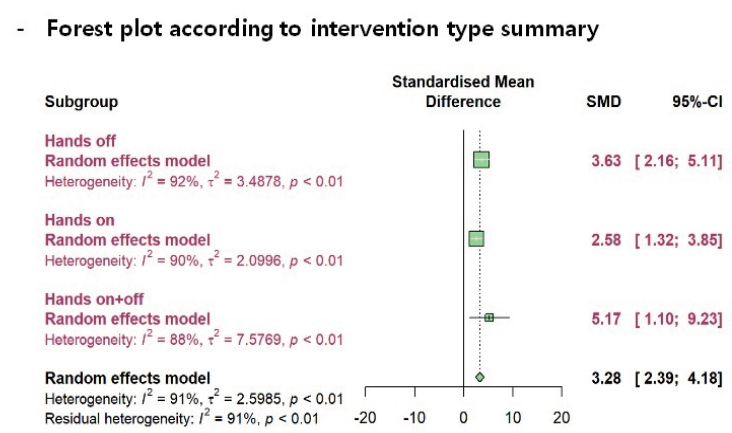

- Forest plot according to intervention

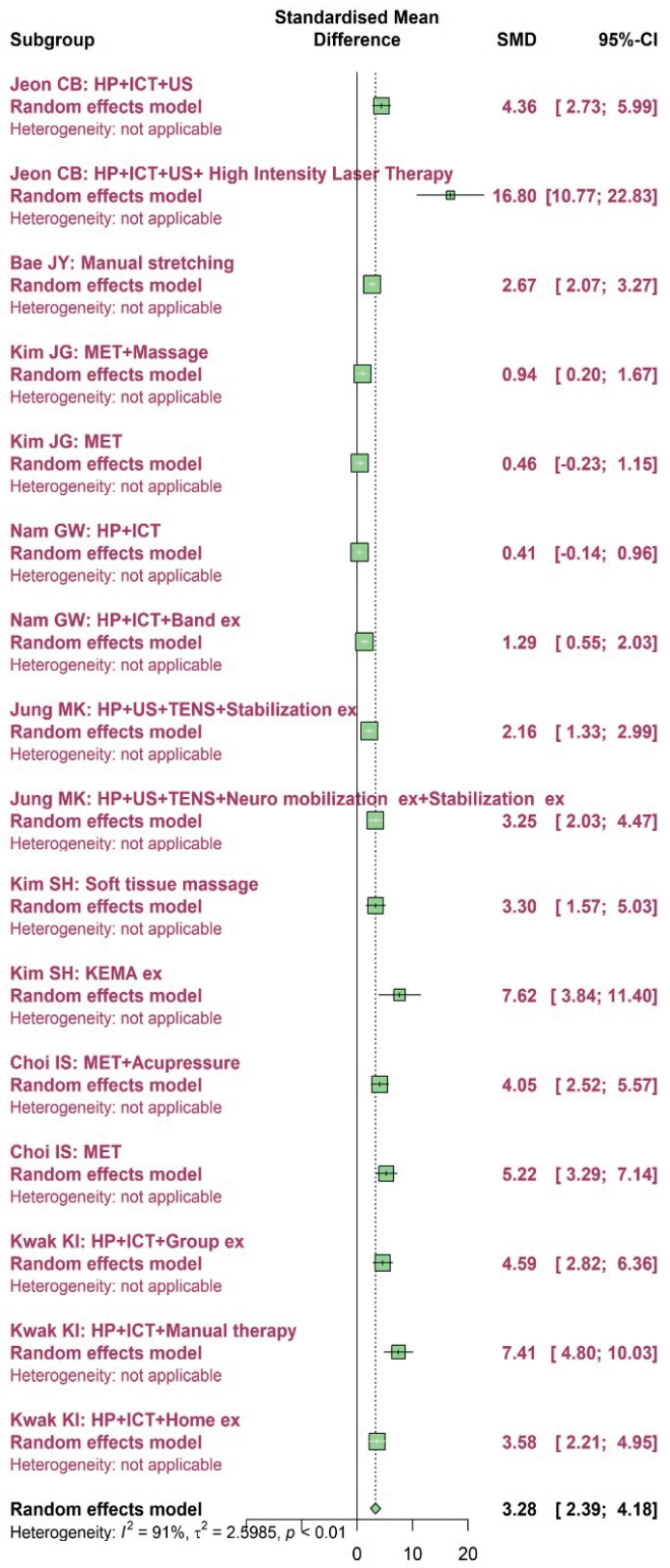

Figure 2. The picture of forest plot according to intervention and outcome. 
통계적으로 유의하지 않은 것으로 나타났고( $\mathrm{p}>0.05)$, 각 중재별 효과 크기는 다음과 같다(Figure 2).

치료 대상자 수에 따른 사례 수와 효과크기는 15 명 이상에서 높게 나타났으며, $95 \%$ 신뢰구간에서 모두 통계적으로 유의하게 나타났으 며, 효과 크기의 차이 $\mathrm{Q}$ 값이 $9.91(\mathrm{df}=1)$ 로 통계적으로 유의한 것으로 나타났다 $(\mathrm{p}<0.05)$. 치료기간에 따른 사례 수는 4 주에서 높게 나타났 고, 효과크기는 8 주에서 높게 나타났으며, $95 \%$ 신뢰구간에서 모두 통 계적으로 유의하게 나타났다. 그러나 효과 크기의 차이 Q값이 1.71 $(\mathrm{df}=2)$ 로 통계적으로 유의하지 않은 것으로 나타났다 $(\mathrm{p}>0.05)$. 치료 횟수에 따른 사례 수와 효과크기는 14명 이하에서 높게 나타났으며, 95\%신뢰구간에서 모두 통계적으로 유의하게 나타났다. 그러나 효과 크기의 차이 $\mathrm{Q}$ 값이 $3.50(\mathrm{df}=1)$ 로 통계적으로 유의하지 않은 것으로 나타났다( $\mathrm{p}>0.05)$. 출판유형에 따른 사례 수는 같고, 효과크기는 학 위논문에서 높게 나타났다. $95 \%$ 신뢰구간에서 모두 통계적으로 유의 하게 나타났으며, 효과 크기의 차이 Q값이 $9.02(\mathrm{df}=1)$ 로 통계적으로 유의한 것으로 나타났다 $(\mathrm{p}<0.05)$ (Table 1).

출간오류에 대한 분석을 위해 'Trim and Fill’을 이용하여, ${ }^{19}$ 비대칭 을 대칭으로 교정한 결과 7 개의 사례가 추가되어 23 개의 사례로 보정
된 효과크기는 $\mathrm{ES}=1.71$ 이며, 통계적으로 유의하게 나타났다 $(\mathrm{p}<0.05)$ (Table 2, Figure 3).

\section{고 찰}

우리 몸에서 관절 운동이 가장 큰 어깨 관절은 넓은 범위에서 손을 자유스럽게 사용할 수 있지만 넓은 관절 운동으로 인해 어깨 관절 부 위에 여러 가지의 질환들이 발생하며, 일차 진료 내원 환자 1,000 명당 6.6-25명이 어깨 관절 문제로 고통 받고 있다. ${ }^{20}$ 어깨 관절 질환 중 가 장 흔한 것이 강직을 동반한 회전근개 질환과 유착성 관절낭염으로 40-60세에서 흔히 발병을 하며 퇴행성 변화와 관계가 있는 것으로 보 고 되고 있으며, ${ }^{21}$ 일상생활에서 필요한 많은 동작들을 수행하거나 보조하며 이러한 어깨관절의 율동적 운동은 근육들의 협조작용에

Table 2. Trim and Fill results

\begin{tabular}{lccccccc}
\hline \multirow{2}{*}{ Publication bias } & \multirow{2}{*}{$\mathrm{k}$} & \multirow{2}{*}{$\mathrm{ES}(\mathrm{g})$} & \multicolumn{2}{c}{$95 \% \mathrm{Cl}$} & \multirow{2}{*}{$\mathrm{Q}(\mathrm{df})$} & $\mathrm{p}$ \\
\cline { 4 - 5 } & & & $\mathrm{LL}$ & $\mathrm{UL}$ & & \\
\hline Trim and Fill & 23 & 1.71 & 0.79 & 2.63 & $271.07(22)$ & $<0.001$ \\
\hline
\end{tabular}

Table 1. Size of the intervention effect according to the control variable

\begin{tabular}{|c|c|c|c|c|c|c|c|}
\hline \multirow{2}{*}{$\begin{array}{l}\text { Control } \\
\text { variable }\end{array}$} & \multirow{2}{*}{$\mathrm{N}$} & \multirow{2}{*}{ k } & \multirow{2}{*}{$\mathrm{ES}(\mathrm{g})$} & \multicolumn{2}{|c|}{$95 \% \mathrm{Cl}$} & \multirow{2}{*}{$\mathrm{Q}(\mathrm{df})$} & \multirow{2}{*}{$\mathrm{p}$} \\
\hline & & & & $\mathrm{LL}$ & UL & & \\
\hline \multirow[t]{2}{*}{ No of participants } & $\geq 15$ & 9 & 4.19 & 3.1 & 5.28 & $9.91(1)$ & $<0.002$ \\
\hline & $\leq 14$ & 7 & 1.85 & 0.89 & 2.82 & & \\
\hline \multirow[t]{3}{*}{ Intervention period (d) } & 4 weeks & 12 & 3.25 & 2.18 & 4.32 & $1.71(2)$ & $>0.425$ \\
\hline & 6 weeks & 2 & 2.61 & 1.56 & 3.67 & & \\
\hline & 8 weeks & 2 & 5.12 & 0.93 & 9.30 & & \\
\hline \multirow[t]{2}{*}{ No of Intervention } & $\leq 14$ & 10 & 3.99 & 2.66 & 5.31 & $3.50(1)$ & $>0.061$ \\
\hline & $\geq 15$ & 6 & 2.29 & 1.12 & 3.47 & & \\
\hline \multirow[t]{2}{*}{ Publication type } & Journal & 8 & 2.08 & 1.06 & 3.10 & $9.02(1)$ & $<0.003$ \\
\hline & Thesis & 8 & 4.34 & 3.27 & 5.42 & & \\
\hline
\end{tabular}

k: Number of effect size, ES: Effect size, 95\% Cl: 95\% Confidence interval, LL: Lower limit, UL: Upper limit, R: Between-study variability.
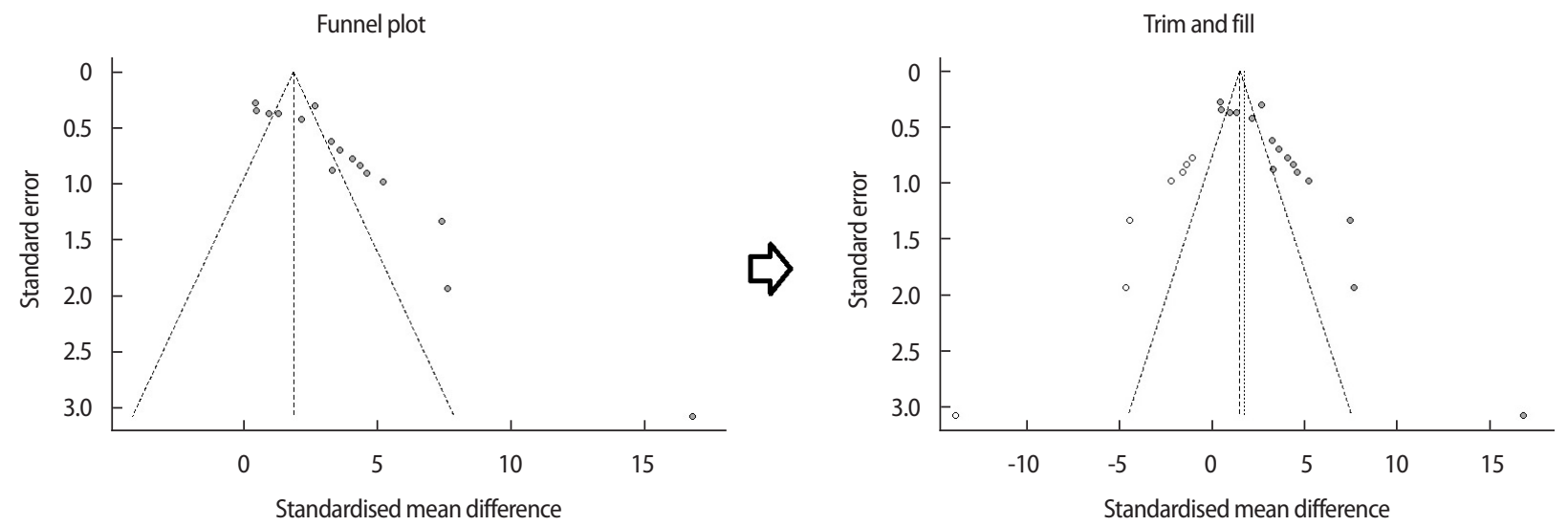

Figure 3. The picture of Funnel plot and Trim and Fill. 
의한 운동성과 근육 및 인대 구조물들의 연합에 의한 안정성에 의해 이루어 지지만, 기립자세에 있어서는 안정성보다는 운동성이 강조되 어 안정성이 매우 취약하며 여러 가지 문제를 유발하기 쉽다.22

본 연구에서는 어깨의 주요 질환인 유착성 관절낭염에 물리치료 를 적용한 국내연구들을 모아서 통증개선에 효과적인 치료방법을 제 시하기 위해체계적이고 종합적인 방법인 메타분석을 통하여 알아보 았다. 연구결과 전체효과크기는 $\mathrm{ES}=3.28$ 이고, 중재유형을 살펴본 결 과 Hands on+off 치료법이 가장 큰 효과크기를 보였다. Rizk 등 23 은 열 치료와 Codman 운동법을 적용한 집단과 경피신경자극치료-활차운 동 병행 치료집단 간 비교에서 경피신경자극치료-활차운동 집단의 관절가동범위가 큰 것으로 나타났고, 도수치료를 받는 유착성 관절 주머니염 환자에게 돌림근띠 강화운동을 추가적으로 시행하는 것이 어깨 통증에 긍정적인 영향을 미치며, 유의한 차이를 보이는 것으로 보고되었다. ${ }^{24}$ 개별 중재에서 가장 높은 효과크기를 세 연구들을 확 인해 본 결과 Jeon 등 ${ }^{4}$ 의 모달리티 치료와 고강도레이저 치료를 함께 적용한 연구가 가장 높은 효과크기 $\mathrm{ES}=16.80$ 를 나타내었다. 저강도 레이저는 주로 세포대사와 상처 치유 촉진 등의 효과가 있으나, 고강 도 레이저는 광물리효과, 광열효과, 광화학효과로 팔굽관절 가쪽위 관절융기염에서 안전하고 비침습적인 방법으로 통증 감소에 효과적 이고 수술 전 치료로 적합하다고 하였고, ${ }^{4}$ Santamato 등 25 은 어깨관절 충돌 증후군 환자 70 명을 대상으로 고강도 레이저 치료와 초음파 치 료 효과를 비교한 연구에서 고강도 레이저 치료가 통증 감소에 더 큰 효과를 나타내었다고 보고하였다. 이러한 결과는 고강도 레이저 치 료가 높은 출력에너지로 심부에 작용하여 생체자극 효과뿐만 아니 라 혈액 순환량이 증가하여 삼출물 제거를 통한 조직 치유가 나타났 기 때문이다.,26

두번째로 높은 효과크기는 운동손상 증후군(KEMA)학회의 교정 운동법이 $\mathrm{ES}=7.62$ 로 나타났다. Griggs 등 ${ }^{27}$ 의 연구에서도 어깨관절 장애 중 특발성 유착성낭염 환자에게 도수교정과 같은 강한 자극을 주는 치료보다는 신장, 운동치료를 적용한 결과가 통증과 기능적 손 상의 경감에 긍정적인 영향을 주었다고 주장하고 있다.

세번째로 높은 효과크기는 모달리티 치료와 도수치료를 함께 적 용한 치료가 $\mathrm{ES}=7.41$ 로 나타났다. 선행연구의 사례에서도 기본 물리 치료 및 도수치료를 포함한 운동치료가 마취하 도수교정이나 스테로 이드 주사치료와 같은 보다 침습적인 동결견 치료보다 효과가 높다 는 것을 주장하고 있으며, ${ }^{28,29} \mathrm{Ma}$ 등 ${ }^{30}$ 은 기본 물리치료와 도수치료를 주 3 회, 4 주간 실시하여 통증과 관절가동범위, 기능적 평가에서 모두 유의한 치료결과를 보고하고 있다.

조절변인에서 치료 대상자수에 대한 사례 수와 효과크기는 15명 이상일 때 효과크기가 높게 나타났으며 통계적으로도 유의하게 나 타났다. 이 결과를 보아 더 많은 대상자에 대한 물리치료 연구가 이루
어 져야 할 것이다. 치료 기간의 경우 4 주 이하의 치료가 많이 이루어 겼음을 알 수 있고, 효과크기는 8주 이상의 기간에서 높게 나타났다. 또한 치료 횟수의 경우도 14 회 이하의 사례가 많은 것을 확인할 수 있 다. 출판유형의 경우 사례수가 같아도 효과크기에서 학위논문의 사 례들이 높은 효과크기를 나타내는 것으로 나타났다. 현재 대부분의 연구들이 개별 중재들의 치료효과를 비교해왔지만 본 연구의 조절변 인 사례를 보아 치료 대상자의 수, 치료 기간, 중재 횟수, 출판 유형에 따른 치료의 효과비교를 분석하는 연구들이 이루어 져야 할 것이다. 본 연구의 메타분석 결과가 타당한지를 검증하기 위해 비대칭을 대칭으로 교정하고 분석한 결과 출간 오류에 의해 보고되지 않았다 고 가정한 7 개의 사례를 추가하여 총 23 개의 사례로 보정된 효과크 기는 $\mathrm{ES}=1.71$ 이며, $95 \% \mathrm{CI}$ 신뢰구간이 $0.79-2.63$ 으로 통계적으로 유의 한 결과를 보아 유착성 관절낭염에 물리치료는 큰 효과가 있다는 것 을 확인할 수 있었고, 개별중재에서 모달리티와 고강도 레이저치료를 함께 적용했을 때와 교정운동만을 적용한 경우, 모달리티와 도수치 료를 함께 적용한 경우의 순으로 각각 높은 효과크기를 보였으며, 이 는 연구자들에 따라 다른 의견과 효과를 주장하는 것을 알 수 있었 다. 또한, 대상자수, 치료기간, 치료횟수의 조절 변인에 의해 영향을 받는 것을 알 수 있었다. 따라서 본 연구 결과는 어깨의 유착성 관절 낭염에 대한 물리치료를 더욱 효과적으로 적용할 수 있도록 객관적 인 메타분석 효과크기 수치 자료를 제시했으며, 유착성 관절낭염에 대한 국내 연구 현황을 체계적이고 고찰해 본 연구이다.

하지만 본 연구에서 고려해야 할 한계로는 첫째, 문헌 선정검토를 전문가와함께 선정하였고 출간오류를 최소화하기 위해 Trim and Fill 을 활용한 보정결과를 제시하였음에도 메타분석이 가진 한계인 출 간오류를 완벽히 해소했다고 할 수는 없을 것이다. 둘째, 연구자들의 대상자 선정과 중재기간 적용 방법들이 서로 다른 이질성을 가지고 있다는 것을 인정하여 무선 효과 모형을 사용한 결과를 제시하였지 만 메타분석의 한계인 서로 다른 연구를 모아 결과를 도출했다는 단 점을 완전히 보완할 수는 없었다. 하지만, 앞으로도 대표적인 질환들 에 대한 국내연구현황을 체계적으로 고찰해보고 객관적인 수치를 제시하는 메타분석이 이루어져야 할 것이다.

\section{REFERENCES}

1. Bjelle A. Epidemiology of shoulder problems. Bailliere's clinical rheumatology. 1989;3(3):437-51.

2. Buschbacher RM. Essentials of musculoskeletal care. Am J Phys Med Rehabil. 2003;82(5):369.

3. Kessel L, Bayley I, Young A. The upper limb: the frozen shoulder. British journal of hospital medicine. 1981;25(4):334-6.

4. Jeon CB, Choi SJ, Oh HJ et al. The effects of high intensity laser therapy on pain and function of patients with frozen shoulder. J Kor Phys Ther. 
2017;29(4):207-10.

5. Rhee KJ. Functional evaluation of shoulder and elbow. Seoul, Young Chang. 2007:675-9.

6. Loew M, Heichel TO, Lehner B. Intraarticular lesions in primary frozen shoulder after manipulation under general anesthesia. J Shoulder Elb Surg. 2005;14(1):16-21.

7. Shaffer B, Tibone JE, Kerlan RK. Frozen shoulder. A long-term followup. JBJS. 1992;74(5):738-46.

8. Choi ES, Kim IS, Lee YS et al. Arthrographic findings of frozen shoulder and therapeutic effect of distension arthrography. J Korean Acad of Rehab Med. 2001;25(2):278-83.

9. Han TR, Bang MS. Rehabilitation medicine. 3rd ed. Seoul, Gunja Publ., 2008:33.

10. Levy O, Rath E, Atar D. Combined treatment for adhesive capsulitis of the shoulder. Harefuah. 1997;133(9):357-9.

11. Jerosch J, Nasef NM, Peters O et al. Mid-term results following arthroscopic capsular release in patients with primary and secondary adhesive shoulder capsulitis. Knee Surg Sports Traumatol Arthrosc. 2013; 21(5):1195-202.

12. Wadsworth CT. Frozen shoulder. Phys Ther. 1986;66(12):1878-83.

13. Glass GV. Primary, secondary, and meta-analysis of research. Educ Res. 1976;5(10):3-8.

14. Jackson GB. Methods for integrative reviews. Rev Educ Res. 1980;50 (3):438-60.

15. Lee HJ, Oh HH, Choi KH. Meta analysis on the effect of reading development program on reading comprehension. J Korean Data Inf Sci Soc. 2012;23(3):447-55.

16. Cohn J. Statistical power analysis for the behavioral sciences. Hillsdale, Lawrence Earlbam Assoc Hillsdale, 1988:25-6.

17. Kim CM, Park JW. Meta-analysis of the effects of physical modality therapy and exercise therapy on neck and shoulder myofascial pain syndrome. Osong Public Heal Res Perspect. 2020;11(4):251-8.

18. Higgins JP, Green S. Cochrane Handbook for Systematic Reviews of Interventions Version 5.1. 0. Chichester, John Wiley \& Sons Ltd., 2011: 276-88.
19. Duval S, Tweedie R. Trim and fill: a simple funnel-plot-based method of testing and adjusting for publication bias in meta-analysis. Biometrics. 2000;56(2):455-63.

20. Van der Windt DA, Koes BW, De Jong BA et al. Shoulder disorders in general practice: incidence, patient characteristics, and management. Ann Rheum Dis. 1995;54(12):959-64.

21. Chun JM, Kim BC, Kim KY. Home treatment of rotator cuff disease. J Korean Orthop Assoc. 1998;33(7):1803-10.

22. Lim WS, Shin HS, Kim IS et al. The effects of scapular pattern and holdrelax technique of PNF on the ROM and VAS in frozen shoulder patients. J Kor Phys Ther. 2002;14(1):15-26.

23. Rizk TE, Gavant ML, Pinals RS. Treatment of adhesive capsulitis (frozen shoulder) with arthrographic capsular distension and rupture. Arch Phys Med Rehabil. 1994;75(7):803-7.

24. Rawat P, Eapen C, Seema KP. Effect of rotator cuff strengthening as an adjunct to standard care in subjects with adhesive capsulitis: a randomized controlled trial. J Hand Ther. 2017;30(3):235-41.

25. Santamato A, Solfrizzi V, Panza F et al. Short-term effects of high-intensity laser therapy versus ultrasound therapy in the treatment of people with subacromial impingement syndrome: a randomized clinical trial. Phys Ther. 2009;89(7):643-52.

26. Pejcic A, Mirkovic D. Anti-inflammatory effect of low level laser treatment on chronic periodontitis. Med Laser Appl. 2011;26(1):27-34.

27. Griggs SM, Ahn A, Green A. Idiopathic adhesive capsulitis: a prospective functional outcome study of nonoperative treatment. J Bone Joint Surg. 2000;82(10):1398.

28. Carette S, Moffet H, Tardif J et al. Intraarticular corticosteroids, supervised physiotherapy, or a combination of the two in the treatment of adhesive capsulitis of the shoulder: a placebo-controlled trial. Arthritis \& rheumatism. 2003;48(3):829-38.

29. Melzer C, Hoffmann S, Wallny T et al. Frozen shoulder-treatment and results. Arch Orthop Trauma Surg. 1995;114(2):87-91.

30. Ma SY, Je HD, Jeong JH et al. Effects of whole-body cryotherapy in the management of adhesive capsulitis of the shoulder. Arch Phys Med Rehabil. 2013;94(1):9-16. 